\title{
Determinants of seizure occurrence in preeclampsia before commencing and during treatment with magnesium sulphate
}

\author{
John O. Imaralu ${ }^{1}$, Olusegun O. Badejoko², Olabisi M. Loto², John C. Ihongbe ${ }^{3}$ \\ ${ }^{1}$ Department of Obstetrics and Gynaecology, Babcock University Teaching Hospital, Ilishan-Remo, Nigeria \\ ${ }^{2}$ Department of Obstetrics and Gynaecology, Obafemi Awolowo University Teaching Hospitals Complex, Ile-Ife, \\ Nigeria \\ ${ }^{3}$ Department of Medical Laboratory Science, Babcock University, Ilishan-Remo, Nigeria
}

Received: 16 August 2016

Accepted: 14 September 2016

\author{
*Correspondence: \\ Dr. John O. Imaralu, \\ E-mail: imaraluj@gmail.com
}

Copyright: () the author(s), publisher and licensee Medip Academy. This is an open-access article distributed under the terms of the Creative Commons Attribution Non-Commercial License, which permits unrestricted non-commercial use, distribution, and reproduction in any medium, provided the original work is properly cited.

\begin{abstract}
Background: Eclampsia is considered as a consequence of severe preeclampsia, with magnesium sulphate regarded as gold standard in seizure treatment and prophylaxis. Convulsions have however been noted when criteria for severe preeclampsia were not met and in patients undergoing treatment with magnesium sulphate.

Methods: A secondary analysis of data obtained from a prospective cross sectional study, involving assessment of clinical and biochemical markers of preeclampsia including magnesium in 75 patients with severe preeclampsia who were given magnesium sulphate using the Pritchard regimen.

Results: Headache $(p=0.002)$, vomiting $(p=0.005)$ and prior occurrence of seizures before presentation $(p=0.001)$, were significant risk factors for occurrence of convulsions. In addition, serum magnesium levels were significantly lower $(1.61 \pm 0.32 \mathrm{mg} / \mathrm{dL})$ among patients who had seizures than in those who did not $(2.01 \pm 0.25 \mathrm{mg} / \mathrm{dL}),(\mathrm{p}<0.001)$. Systolic blood pressure $(p=0.22)$, diastolic blood pressure $(p=0.29)$, mean arterial blood pressure $(p=0.17)$ and proteinuria $(\mathrm{p}=0.18$ ) however did not determine the occurrence of seizures. Only $3 / 49(6.1 \%)$ of the patients with severe hypertension (MAP $\geq 125 \mathrm{mmHg}$ ) fitted, compared to $6 / 26(23.1 \%)$ with mild hypertension (MAP $<125 \mathrm{mmHg})$ who convulsed $(\mathrm{p}=0.04)$. Convulsion during treatment with MgS04 was associated with significantly lower levels of serum magnesium $(4.04 \pm 0.5 \mathrm{mg} / \mathrm{dL})$, than $4.63 \pm 0.5 \mathrm{mg} / \mathrm{dL}$ observed among patients with severe preeclampsia who did not convulse $(\mathrm{p}=0.04)$.

Conclusions: Headache, vomiting, prior convulsion and low serum magnesium levels preceded the occurrence of fits before treatment while, prior convulsion and low serum magnesium level consistently preceded the occurrence of fits during treatment of preeclampsia with magnesium sulphate.
\end{abstract}

Keywords: Eclampsia, Prediction, Seizures, Preeclampsia, Magnesium sulphate

\section{INTRODUCTION}

Eclampsia is defined as the occurrence of generalised tonic-clonic convulsions in a pregnant or recently delivered woman with preeclampsia. ${ }^{1}$ About 1 to $2 \%$ of all cases of severe preeclampsia are complicated by seizures. $^{2}$ Preeclampsia is one of the hypertensive disorders of pregnancy with multi-systemic effects; it is characterised by hypertension and proteinuria occurring after the $20^{\text {th }}$ week of pregnancy in a woman who has been previously normotensive and non-proteinuric. ${ }^{1}$

Preeclampsia is categorised as 'mild' or 'severe' based on extent of hypertension, the degree of proteinuria and the presence of symptoms or complications. Mild preeclampsia is defined as blood pressure of $\geq 140 \mathrm{~mm} \mathrm{Hg}$ systolic or $\geq 90 \mathrm{~mm} \mathrm{Hg}$ diastolic on at least two occasions and at least 4 to 6 hours apart after the 20th week of 
gestation with proteinuria (defined as $\geq 300 \mathrm{mg}$ protein in a 24 hour urine specimen) in women who were previously normotensive and had no proteinuria. ${ }^{3}$ Severe preeclampsia is defined as blood pressure $\geq 160 \mathrm{~mm} \mathrm{Hg}$ systolic, $\geq 110 \mathrm{~mm} \mathrm{Hg}$ diastolic, or both, accompanied by $\geq 5 \mathrm{~g}$ of proteinuria per day. The presence of symptoms such as headache, visual disturbance, epigastric pain, vomiting, multi-organ system involvement, fetal morbidity or mortality or seizures in a patient with preeclampsia is also considered as severe preeclampsia. ${ }^{1,3}$

Approximately 63,000 women worldwide die of preeclampsia and eclampsia every year; $99 \%$ of these deaths occur in low-income countries. ${ }^{4}$ The reported incidence of eclampsia in developed countries is $1 / 2000$, while it varies in developing countries, from 1/500 to $1 / 50$ deliveries. ${ }^{5,6}$ Preeclampsia has been referred to as a disease of theories; as the exact course of events that lead to the clinical syndrome have not been fully elucidated. Although the exact aetiology remains undetermined, two basic pathologies are consistently seen in preeclampsia; abnormal trophoblastic invasion of uterine blood vessels and endothelial cell dysfunction., ${ }^{7,8}$

Although the pathway to occurrence of seizures during preeclampsia is poorly understood, alterations in the functioning of the cerebral vasculature and disruptions in cerebral blood flow auto-regulation are two mechanisms postulated to underlie the occurrence of fits in these patients. ${ }^{9,10}$ Clinical findings showing varying degrees of cerebral haemorrhage, edema and vascular dysfunction (which are effects of cerebral circulatory dysfunction) have also been linked with eclampsia. ${ }^{11}$

Eclamptic fits may be recurrent, in the same pregnancy with each episode lasting 1-2 minutes, often within a short period lasting between 3 and 12 hours. ${ }^{12}$ These seizures cause cessation of respiration in the mother, resulting in hypoxia and lactic acidosis; the ensuing fetal bradycardia may persist for up to 20 minutes. ${ }^{13}$ Sudden memory loss also complicates eclampsia and this may prevail for periods lasting hours to days, especially after repeated episodes of seizures. ${ }^{12}$ In addition, eclampsia can also cause intracerebral haemorrhage, cerebral edema, acute renal failure, pulmonary edema and aspiration pneumonitis, which are leading causes of maternal death. ${ }^{11,14}$

Preeclampsia remains an unpreventable condition today, although great advances are being made in the prediction of its occurrence. Unlike preeclampsia however, eclampsia can be considered as a preventable condition, together with its sequela. ${ }^{15}$ Magnesium sulphate is the anticonvulsant of choice in the treatment and prevention of convulsions associated with preeclampsia and it has been shown in the MAGPIE trial to cut the risk of seizures occurring by more than half. ${ }^{16}$ Effective anticonvulsant serum levels of magnesium however range from 4.8 to $8.4 \mathrm{mg} / \mathrm{dL} .{ }^{17}$ Studies have associated low levels of serum ionized magnesium with occurrence of convulsions in preeclampsia. ${ }^{18-20}$

Patients with severe preeclampsia have been traditionally regarded as being at greater risk for development of seizures and thus are given preference for administration of prophylactic anticonvulsants. ${ }^{21}$ Since magnesium sulphate did not prevent seizures in all the patients who met the criteria for administration, in the MAGPIE trial, it is imperative to determine the characteristics of patients who convulse while on treatment with magnesium sulphate. Reports from some studies have suggested a poor link between occurrence of fits and degree of hypertension or proteinuria, thus questioning the practice of associating convulsions mainly with the increasing severity of preeclampsia based on worsening hypertension and proteinuria. ${ }^{22-24}$ This study therefore aimed to determine the clinical and biochemical features of preeclampsia that could predict the occurrence of fits, in patients with severe preeclampsia before commencing and during treatment with magnesium sulphate.

\section{METHODS}

This study is a secondary analysis of data obtained from a prospective cross-sectional study, in women who were given magnesium sulphate using the Pritchard regimen for seizure prophylaxis in severe preeclampsia and eclampsia; conducted in the Department Of Obstetrics and Gynecology of the Obafemi Awolowo University Teaching Hospitals Complex (OAUTHC) located in IleIfe, Osun state, South-Western Nigeria. ${ }^{25}$ Data were obtained over a six-month period from the two units of the Hospital. Ethical approval was obtained from the research and ethics committee of the institution (Protocol number ERC/2012/06/05).

Consecutive patients aged between 18 and 45 years, with singleton pregnancies, gestational ages 28 and 41 weeks, or in the puerperium; admitted for severe preeclampsia or eclampsia were included in the study while patients with pregnancies less than 28 weeks or more than 41 weeks, mild preeclampsia, personal or family history of myasthenia gravis, diabetes mellitus, renal disease, cardiac disease and those with allergy to magnesium sulphate, or who had previously received other anticonvulsants were excluded from the study. Data were obtained only after written informed consent from participants or an adult relative, where the extent of the disease precluded it. The sample size was calculated based on the serum magnesium level among severe preeclamptic patients in the third trimester. The values obtained by Preedatham et al of $4.90 \pm 1.90 \mathrm{mg} / \mathrm{dl}$ among women with severe preeclampsia treated with magnesium sulphate and that obtained by Phuapradit et al of $2.3 \pm 0.30$ $\mathrm{mg} / \mathrm{dl}$ among women with severe preeclampsia who had not commenced magnesium sulphate were applied to the formula for comparison of means: $\mathrm{n}=(\mathrm{u}+\mathrm{v})^{2}$ $\left(\sigma_{1}^{2}+\sigma 0^{2}\right) /\left(\mu^{1}-\mu^{0}\right) .^{26-28}$ 
Type II error margin for this study was set at 0.1 , implying a power of $90 \%$. A minimum sample size of 67 was obtained after adding $10 \%$ for attrition. All participants received the standard Pritchard regimen of magnesium sulphate administration thus: a loading dose of $4 \mathrm{~g}$ (of $20 \%$ solution) intravenous magnesium sulphate over 10-15 minutes, followed immediately by $10 \mathrm{~g}$ (of $50 \%$ solution) of deep intramuscular magnesium sulphate ( $5 \mathrm{~g}$ on each buttock), in the upper outer quadrant of each buttock. A maintenance dose of $5 \mathrm{~g}$ intramuscular magnesium sulphate was thereafter administered every 4 hours on alternate buttocks for 24 hours.

The presence of symptoms and signs were assessed at admission followed by blood pressure, respiratory rate, urinary output, dip stick urinalysis, tendon reflexes and serum magnesium level which were monitored before each dose of $\mathrm{MgSO}_{4}$. Absent tendon reflexes and/or respiratory rate $<16 /$ minute were considered as clinical evidence of toxicity. Calcium gluconate $(10 \mathrm{ml}$ of $1 \%)$ was made available for management of overdose or toxicity. Urine protein was measured by dipstick and graded on a scale of 0 to $4+$, thus: 0 (negative), trace (15$30 \mathrm{mg} / \mathrm{dl}), 1+(30-100 \mathrm{mg} / \mathrm{dl}), 2+(100-300 \mathrm{mg} / \mathrm{dl}), 3+$ $(300-1000 \mathrm{mg} / \mathrm{dl})$ and $4+(>1000 \mathrm{mg} / \mathrm{dl}){ }^{1}$
Serum magnesium assay was done on $5 \mathrm{ml}$ of venous blood obtained from each patient before each dose of $\mathrm{MgSO}_{4}$ i.e before the loading dose and at the; 4, 8, 12, 16, 20 and 24-hour maintenance doses. Magnesium quantitation was done using the Atomic Absorption Spectrophotometry (AAS 100 machine, Varian Technologies, Inc. Australia). The data obtained were processed using SPSS version 15.0 (SPSS Inc, Chicago; IL). Univariate and bivariate analysis was done and the student t-test used for comparison of means in independent samples, while Chi-square test was used to compare categorical variables. The $95 \%$ confidence interval was used and the level of statistical significance set at p-value of $<0.05$.

\section{RESULTS}

A total of 75 patients participated in the study over a period of six months. There were no statistically significant differences in age $(p=0.41)$, parity $(p=6.42)$, social class $(\mathrm{p}=1.00)$, educational level $(\mathrm{p}=0.88)$, antenatal care booking status $(\mathrm{p}=0.55)$ and gestational age at presentation $(\mathrm{p}=0.36)$, between the patients who convulsed and those who did not. The BMI $(\mathrm{p}=0.02)$ and presence of multiple gestation $(p=0.03)$ was however significantly different between those who convulsed and those who did not (Table 1).

Table 1: Socio-biologic characteristics of patients and occurrence of seizures before treatment.

\begin{tabular}{|c|c|c|c|c|c|}
\hline \multirow{2}{*}{ Bio data } & \multicolumn{2}{|c|}{ Occurrence of fits } & \multirow{2}{*}{ Total $(n=75)$} & \multirow{2}{*}{ p-Value } & \multirow{2}{*}{ OR (95\% CI) } \\
\hline & Yes $(n=9)$ & No $(n=66)$ & & & \\
\hline Age (years) & $25.6 \pm 6.1$ & $27.4 \pm 6.3$ & $27.19 \pm 6.2$ & 0.41 & -6.66 to 2.95 \\
\hline \multicolumn{4}{|l|}{ Parity } & \multirow{3}{*}{0.62} & \\
\hline Primigravida & 5 & 37 & 42 & & \\
\hline Multipara & 4 & 29 & 33 & & \\
\hline \multicolumn{4}{|l|}{ Social class } & \multirow{4}{*}{0.75} & \\
\hline High & 0 & 1 & 1 & & \\
\hline Middle & 4 & 30 & 34 & & \\
\hline Low & 5 & 35 & 40 & & \\
\hline \multicolumn{4}{|l|}{ Educational level } & \multirow{4}{*}{0.88} & \multirow{4}{*}{$0.87-0.88$} \\
\hline Tertiary & 0 & 7 & 7 & & \\
\hline Secondary & 6 & 37 & 43 & & \\
\hline Primary & 3 & 32 & 35 & & \\
\hline \multicolumn{4}{|l|}{ Booking status } & \multirow{3}{*}{0.55} & \multirow{3}{*}{$1.27(0.29-5.62)$} \\
\hline Unbooked & 7 & 48 & 55 & & \\
\hline Booked & 2 & 18 & 20 & & \\
\hline Gestational age (weeks) & $36.0 \pm 3.3$ & $36.2 \pm 3.2$ & $36.4 \pm 3.0$ & 0.86 & -2.77 to -2.31 \\
\hline \multicolumn{4}{|l|}{ No. of fetuses } & \multirow{4}{*}{0.03} & \multirow{4}{*}{$0.03-0.04$} \\
\hline Singleton & 6 & 59 & 65 & & \\
\hline Twin & 2 & 7 & 9 & & \\
\hline Triplet & 1 & 0 & 1 & & \\
\hline \multicolumn{4}{|l|}{ Sex of baby } & \multirow{3}{*}{0.93} & \multirow{3}{*}{$1.06(0.29-3.90)$} \\
\hline Male $(n=49)$ & 6 & 43 & 49 & & \\
\hline Female $(n=26)$ & 3 & 23 & 26 & & \\
\hline BMI $\left(\mathrm{kg} / \mathrm{m}^{2}\right)$ & $23.8 \pm 3.5$ & $27.7 \pm 3.4$ & $27.4 \pm 3.5$ & 0.02 & -3.89 to -1.62 \\
\hline
\end{tabular}

OR= Odds Ratio; $95 \% \mathrm{CI}=95 \%$ Confidence interval. 
Table 2: Relationships between symptoms of preeclampsia and occurrence of seizures.

\begin{tabular}{|c|c|c|c|c|c|}
\hline \multirow{2}{*}{ Symptoms } & \multicolumn{2}{|c|}{ Occurrence of fits } & \multirow[b]{2}{*}{ Total $(\mathrm{n}=75)$} & \multirow[b]{2}{*}{ p-Value } & \multirow[b]{2}{*}{ OR $(95 \% \mathrm{CI})$} \\
\hline & Yes $(n=9)$ & No $(n=66)$ & & & \\
\hline \multicolumn{4}{|l|}{ Headache } & \multirow{3}{*}{0.02} & \multirow{3}{*}{$4.82(1.32-17.57)$} \\
\hline Yes $(\%)$ & $6(27.3)$ & $16(72.7)$ & 22 & & \\
\hline No $(\%)$ & $3(5.7)$ & $50(94.3)$ & 53 & & \\
\hline \multicolumn{4}{|c|}{ Visual disturbance } & \multirow{3}{*}{0.38} & \multirow{3}{*}{$0.64(0.17-2.35)$} \\
\hline Yes $(\%)$ & $3(9.1)$ & $30(90.9)$ & 33 & & \\
\hline No $(\%)$ & $6(14.3)$ & $36(85.7)$ & 42 & & \\
\hline \multicolumn{4}{|c|}{ Abdominal pain } & \multirow{3}{*}{0.59} & \multirow{3}{*}{$0.93(0.27-3.19)$} \\
\hline Yes $(\%)$ & $5(11.6)$ & $38(88.4)$ & 43 & & \\
\hline No $(\%)$ & $4(12.5)$ & $28(87.5)$ & 32 & & \\
\hline \multicolumn{4}{|l|}{ Insomnia } & \multirow{3}{*}{0.45} & \multirow{3}{*}{$0.75(0.22-2.54)$} \\
\hline Yes $(\%)$ & $5(10.6)$ & $42(89.4)$ & 47 & & \\
\hline No $(\%)$ & $4(14.3)$ & $24(85.7)$ & 28 & & \\
\hline \multicolumn{4}{|l|}{ Vomiting } & \multirow{3}{*}{0.005} & \multirow{3}{*}{$7.00(1.57-31.26)$} \\
\hline Yes $(\%)$ & $7(28.0)$ & $18(72.0)$ & 25 & & \\
\hline No (\%) & $2(4.0)$ & $48(96.0)$ & 50 & & \\
\hline \multicolumn{4}{|l|}{ Malaise } & \multirow{3}{*}{0.52} & \multirow{3}{*}{$0.83(0.24-2.85)$} \\
\hline Yes (\%) & $5(11.1)$ & $40(88.9)$ & 45 & & \\
\hline No (\%) & $4(13.3)$ & $26(86.7)$ & 30 & & \\
\hline
\end{tabular}

Table 3: Relationships between signs of preeclampsia and occurrence of fits.

\begin{tabular}{|c|c|c|c|c|c|}
\hline \multirow[b]{2}{*}{ Features } & \multicolumn{2}{|c|}{ Occurrence of fits } & \multirow[b]{2}{*}{ Total } & \multirow{2}{*}{ p-Value } & \multirow{2}{*}{ OR $(95 \% \mathrm{CI})$} \\
\hline & Yes $(n=9)$ & No $(n=66)$ & & & \\
\hline Systolic BP (mmHg) & $162.2 \pm 20.5$ & $172.0 \pm 23.4$ & $170.8 \pm 23.1$ & 0.22 & $(-26.04$ to -6.55$)$ \\
\hline Diastolic BP (mmHg) & $103.3 \pm 12.3$ & $108.2 \pm 10.8$ & $107.6 \pm 11.0$ & 0.29 & $(-14.45$ to -4.75$)$ \\
\hline $\mathrm{MAP}(\mathrm{mmHg})$ & $123.0 \pm 13.9$ & $129.4 \pm 13.2$ & $128.7 \pm 13.3$ & 0.17 & $(-15.85$ to -2.89$)$ \\
\hline \multicolumn{4}{|l|}{ MAP(severity) } & \multirow{3}{*}{0.04} & \multirow{3}{*}{$0.27(0.07-0.98)$} \\
\hline$\geq 125 \mathrm{mmHg}(\%)$ & $3(6.1 \%)$ & $46(93.9 \%)$ & 49 & & \\
\hline$<125 \mathrm{mmHg}(\%)$ & $6(23.1 \%)$ & $20(76.9 \%)$ & 26 & & \\
\hline \multicolumn{4}{|l|}{ Proteinuria } & \multirow{5}{*}{0.18} & \multirow{5}{*}{$0.17-0.19$} \\
\hline $1+$ & 2 & 14 & 16 & & \\
\hline $2+$ & 1 & 13 & 14 & & \\
\hline $3+$ & 5 & 39 & 44 & & \\
\hline $4+$ & 0 & 1 & 1 & & \\
\hline \multicolumn{4}{|l|}{ Convulsion before arrival } & \multirow{3}{*}{0.001} & \multirow{3}{*}{$13.43(1.77-101.78)$} \\
\hline Yes $(\%)$ & $8(28.6)$ & $20(71.4)$ & 28 & & \\
\hline No $(\%)$ & $1(2.1)$ & $46(97.9)$ & 47 & & \\
\hline \multicolumn{4}{|l|}{ Deep tendon reflexes } & \multirow{3}{*}{0.19} & \\
\hline Normal (\%) & $9(14.8)$ & $52(85.2)$ & 61 & & \\
\hline Hyper-reflexia $(\%)$ & $0(0)$ & $14(100)$ & 14 & & \\
\hline \multicolumn{4}{|l|}{ Complications of preeclampsia } & \multirow{6}{*}{0.03} & \multirow{6}{*}{$(0.03-0.04)$} \\
\hline None & 7 & 60 & 67 & & \\
\hline Placental abruption & 0 & 4 & 4 & & \\
\hline Aspiration pneumonitis & 2 & 0 & 2 & & \\
\hline Pulmonary oedema & 0 & 1 & 1 & & \\
\hline Stroke & 0 & 1 & 1 & & \\
\hline Serum magnesium level (mg/dL) & $1.61 \pm 0.32$ & $2.01 \pm 0.25$ & $1.96 \pm 0.29$ & 0.001 & $(-0.59$ to -0.21$)$ \\
\hline
\end{tabular}

The presence of headache $(\mathrm{p}=0.002, \mathrm{OR}=4.82,95 \% \mathrm{CI}$ of 1.32-17.57) and occurrence of vomiting ( $\mathrm{p}=0.005$, OR
$=7.00,95 \%$ CI of $1.57-31.26)$ were also significantly different between patients who convulsed and those who 
did not. This was not the case however for visual disturbance $(\mathrm{p}=0.38)$, abdominal pain $(\mathrm{p}=0.59)$, insomnia $(p=0.45)$ and malaise $(p=0.52)$ as they were not similar between these 2 outcomes (Table 2).

Systolic blood pressure $(\mathrm{p}=0.22)$, diastolic blood pressure $(\mathrm{p}=0.29)$ and mean arterial blood pressure $(\mathrm{p}=$ 0.17 ) did not determine the occurrence of seizures as no difference existed between those who fitted and patients who did not. In addition only 3/49 (6.1\%) of the patients with severe hypertension (MAP $\geq 125 \mathrm{mmHg}$ ) fitted, compared to $6 / 26(23.1 \%)$ with mild hypertension (MAP $<125 \mathrm{mmHg})$ who convulsed $(\mathrm{p}=0.04)$. In another way, $3 / 9(33.3 \%)$ of patients who convulsed before commencing magnesium sulphate, had severe hypertension (MAP $\geq 125 \mathrm{mmHg}$ ) compared to $40 / 66$ $(69.7 \%)$ of those who did not convulse. Table 3 also shows that the degree of proteinuria $(p=0.18)$ and deep tendon reflexes $(p=0.19)$ were not significantly different between pre-eclamptics who convulsed and those who did not.

Prior occurrence of seizures in index pregnancy, before presentation to the hospital $(\mathrm{p}=0.001, \mathrm{OR}=13.43,95 \%$ $\mathrm{CI}$; 1.77-101.78) and presence of complications of preeclampsia at admission $(\mathrm{p}=0.03)$ were significant risk factors for occurrence of fits in the hospital. In addition, serum magnesium levels were observed to be significantly lower $(1.61 \pm 0.32 \mathrm{mg} / \mathrm{dL})$ among patients who had seizures than in those who did not $(2.01 \pm 0.25$ $\mathrm{mg} / \mathrm{dL}$ ), $\mathrm{p}<0.001$ (Table 3).

Table 4: Determinants of convulsion during treatment with $\mathrm{MgSO}_{4}$.

\begin{tabular}{|c|c|c|c|c|c|}
\hline \multirow{2}{*}{ Factor } & \multicolumn{2}{|c|}{ Occurrence of fits } & \multirow{2}{*}{ Total $(n=75)$} & \multirow{2}{*}{ p-Value } & \multirow{2}{*}{ OR $(95 \% \mathrm{CI})$} \\
\hline & Yes $(n=3)$ & No $(n=72)$ & & & \\
\hline \multicolumn{4}{|l|}{ Convulsion before arrival } & \multirow{3}{*}{0.049} & \\
\hline Yes $(\%)$ & $3(10.7 \%)$ & $25(89.3 \%)$ & 28 & & \\
\hline No $(\%)$ & $0(0)$ & $47(100 \%)$ & 47 & & \\
\hline BMI $\left(\mathrm{kg} / \mathrm{m}^{2}\right)$ & $22.7 \pm 5.2$ & $27.6 \pm 3.4$ & $27.4 \pm 3.5$ & 0.06 & -9.84 to 0.10 \\
\hline MAP at first $\mathrm{MgSO}_{4}$ dose & $128.9 \pm 13.5$ & $128.7 \pm 13.4$ & $128.7 \pm 13.3$ & 0.98 & -15.50 to 15.57 \\
\hline \multicolumn{4}{|l|}{ Severe hypertension at first $\mathrm{MgSO}_{4}$} & \multirow{3}{*}{0.73} & \multirow{3}{*}{$1.06(0.10-11.16)$} \\
\hline$\geq 125 \mathrm{mmHg}$ & 2 & 47 & 49 & & \\
\hline$<125 \mathrm{mmHg}$ & 1 & 25 & 26 & & \\
\hline \multicolumn{4}{|l|}{ Proteinuria } & \multirow{5}{*}{0.39} & \multirow{5}{*}{$0.38-0.40$} \\
\hline $1+$ & 1 & 15 & 16 & & \\
\hline $2+$ & 1 & 13 & 14 & & \\
\hline $3+$ & 1 & 43 & 44 & & \\
\hline $4+$ & 0 & 1 & 1 & & \\
\hline \multicolumn{4}{|l|}{ LD-delivery interval } & \multirow{3}{*}{0.35} & \multirow{3}{*}{$3.00(0.29-31.63)$} \\
\hline$<4$ hours & 2 & 28 & 30 & & \\
\hline$\geq 4$ hours & 1 & 44 & 45 & & \\
\hline Placental weight $(\mathrm{g})$ & $460.0 \pm 198.0$ & $505.8 \pm 118.8$ & $493.2 \pm 119.3$ & 0.60 & -218.5 to 126.8 \\
\hline Admission-first $\mathrm{MgSO}_{4}$ interval (mins) & $28.2 \pm 16.2$ & $52.3 \pm 18.5$ & $49.0 \pm 19.7$ & $<0.001$ & -37.01 to -11.14 \\
\hline Magnesium Mg levels 4 hours after LD & $4.04 \pm 0.5$ & $4.63 \pm 0.5$ & $4.60 \pm 0.5$ & 0.04 & -1.15 to -0.01 \\
\hline \multicolumn{4}{|c|}{ Therapeutic $\mathrm{Mg}$ levels at 4 hours $(\geq 4.8 \mathrm{mg} / \mathrm{dL})$} & \multirow{3}{*}{0.26} & \multirow{3}{*}{$0.93(0.86-1.01)$} \\
\hline Not Attained & 3 & 41 & 44 & & \\
\hline Attained & 0 & 31 & 31 & & \\
\hline
\end{tabular}

$\mathrm{MgSO}_{4}=$ Magnesium sulphate $;$ Mins = Minutes; $\mathrm{LD}=$ Loading dose.

All convulsions after commencing magnesium sulphate therapy occurred in the interval between the loading dose of the Pritchard regimen and the 4-hour maintenance. The interval between admission and administration of the first dose of magnesium sulphate was significantly shorter $(\mathrm{p}<0.001)$ in the patients that convulsed $(28.2 \pm 16.2$ minutes) than in the patients who had no seizures (52.3 \pm 18.5 minutes). The $\mathrm{MgSO}_{4}$ loading dose-delivery interval was however comparable between participants who fitted and those who did not $(\mathrm{p}=0.35)$. Convulsion during treatment with $\mathrm{MgSO}_{4}$ was associated with significantly lower levels of serum magnesium (4.04 \pm 0.5 $\mathrm{mg} / \mathrm{dL})$, than the absence of convulsion $(4.63 \pm 0.5$ $\mathrm{mg} / \mathrm{dL}), \mathrm{p}=0.045$. However, most of the participants $44 / 75(58.7 \%)$ had serum magnesium levels below the therapeutic range $(<4.80 \mathrm{mg} / \mathrm{dL}), 4$ hours after receiving the loading dose of the Pritchard regimen for magnesium sulphate administration. In fact all $3(100 \%)$ of the patients who convulsed during magnesium sulphate therapy had sub-therapeutic range magnesium levels at 
this time. The degree of proteinuria $(p=0.39)$ and the placental weight $(\mathrm{p}=0.60)$ were found to be comparable between the participants that convulsed and those who did not (Table 4).

\section{DISCUSSION}

The socio-biologic factors; age, parity and socioeconomic status, which are recognized risk factors for preeclampsia were similar between patients who convulsed and those who did not, suggests that occurrence of convulsions, may not necessarily be a result of the severity of preeclampsia. Pre-eclamptics who were unbooked have been regarded as being at increased risk for convulsions, because poor or lack of antenatal care has been associated with risk of complications of preeclampsia which includes seizures, there is however no significant difference in the booking status between the two groups. This suggests possible difficulty in identifying preeclamptics at increased risk of convulsion. ${ }^{29}$ The finding of a higher occurrence of fits among patients with multiple gestation however, corroborates postulates of eclampsia as - a disease of the trophoblast (which has been established in preeclampsia), with increased risk when more placentas exist. The incidence of eclampsia is reportedly higher in multi-fetal gestations.30 Headache and vomiting were the most consistent symptoms that preceded convulsions in this study. Association of headache with seizures agrees with reports from some earlier studies. $^{23,31,32}$ Vomiting which can be an effect of neurological involvement in preeclampsia (even though neurological affectation also explains occurrence of eclampsia) was however not found to precede eclampsia in a study in Tanzania on features of imminent eclampsia. ${ }^{32}$ The finding that visual disturbance was not a significant determinant, in this study, however contrasts what was earlier reported. ${ }^{31}$

The degree of proteinuria and hypertension defining preeclampsia were not significant predictors of occurrence of seizures, even though they are recognized measures of severity of preeclampsia. A significantly smaller proportion of $6.1 \%$ of patients with severe hypertension in this study convulsed, compared to the larger proportion of $23.1 \%$ with mild hypertension who did. The finding in this study that only $33 \%$ of the participants who convulsed had severe hypertension is in consonance with a reported of a study where it was observed that only $38 \%$ of women who developed eclampsia had hypertension and proteinuria prior to the onset of seizures. ${ }^{33}$ Reports from another study in the United Kingdom revealed that hypertension $(\geq 120 \mathrm{mmHg}$ diastolic) was recorded in only $20 \%$ of patients with eclampsia. $^{23}$ The findings from this study are also in agreement with some earlier studies which consistently found that there is little correlation between blood pressure and the occurrence of seizures in pregnancy. ${ }^{10,22-}$ ${ }^{24}$ These findings suggest that seizures may not be a progression from mild preeclampsia to severe preeclampsia, to eclampsia.
Significantly lower magnesium levels were observed among patients who convulsed, before commencing $\mathrm{MgSO}_{4}$; this finding is in consonance with earlier reports where low serum magnesium levels have been linked with occurrence of seizures in preeclampsia; a fact that has been suggested as the reason for the efficacy of magnesium sulphate in prevention of convulsions. ${ }^{18-20}$ Patients who convulsed before arriving the hospital had a greater risk of convulsing again, suggesting an unresolved predisposition to seizures at this time. $\mathrm{MgSO}_{4}$ a cerebral N-methyl-D-Aspartate (NMDA) receptor antagonist has been shown to have better anti-convulsant effect with increasing cerebral concentrations. ${ }^{34}$

The patients admitted for eclampsia had shorter, intervals between admission and first dose of $\mathrm{MgSO}_{4}$, this is because some of them actually convulsed at arrival and had early resuscitation including seizure treatment and prophylaxis. All seizures while on treatment with $\mathrm{MgSO}_{4}$ occurred in the interval between the loading (first) dose and the 4 hour maintenance. At this time, it was observed that most $(58.7 \%)$ of the participants had serum Magnesium levels below the therapeutic range. A similar finding had been earlier observed in Sokoto, Northern Nigeria and Istanbul in Turkey, where most of the patients with eclampsia had serum magnesium levels in the lower $50 \%$ of the therapeutic range. ${ }^{35,36}$ These above observations suggest that although the anticonvulsant effect of intravenous magnesium is immediate and serum levels peak in 15 minutes; it appears that a critical level of serum magnesium (close to or within the therapeutic range) needs to be attained in order to prevent convulsions. ${ }^{37}$ Thus low serum magnesium levels consistently preceded occurrence of fits before commencing and during treatment of preeclampsia with magnesium sulphate.

\section{CONCLUSION}

Headache, vomiting, prior convulsion and low serum magnesium levels consistently preceded the occurrence of fits before treatment, while prior convulsion and low serum magnesium level consistently preceded the occurrence of fits during treatment of preeclampsia with magnesium sulphate.

\section{ACKNOWLEDGEMENTS}

The investigators express sincere gratitude to the residents, midwives and porters, in the maternity unit of the OAUTHC, Ile-Ife and the staff of the Central Science Laboratory of the Obafemi Awolowo University Ile-Ife for the valuable roles in the conduct of this study.

Funding: for this research was provided by the investigators

Conflict of interest: None declared

Ethical approval: The study was approved by the Institutional Ethics Committee (Protocol number: ERC/2012/06/05 


\section{REFERENCES}

1. Report of the National high blood pressure education program working group on high blood pressure in pregnancy. Am J Obstet Gynecol. 2000;183:S1-22.

2. Steegers EA, von Dadelszen P, Duvekot JJ, Pijnenborg R. Preeclampsia. The Lancet. 2010;376:631-44.

3. Sibai B, Dekker G, Kupferminc M. Preeclampsia. The Lancet. 2005;365(9461):785-99.

4. Langer A, Villar J, Tell K, Kim T, Kennedy S. Reducing eclampsia-related deaths a call to action. Lancet. 2008;371(9614):705-6.

5. Waugh JJ, Clark TJ, Divakaran TG, Khan KS, Kilby MD. Accuracy of urinalysis dipstick technique in predicting significant proteinuria in pregnancy. Obstet Gynaecol. 2004:103:769-77.

6. Ozumba BC, Ibe AI. Eclampsia in Enugu, eastern Nigeria. Acta Obstet Gynecol Scand. 1993;72(3):189-92.

7. Redman CING, Sacks GP, Sargent IL. Preeclampsia NA excessive maternal inflammatory response to pregnancy. Am J Obstet Gynecol. 1999;180(2):499506.

8. James JL, Whitley GS, Cartwright JE. Preeclampsia: fitting together the placental, immune and cardiovascular pieces. J Patho. 2010;221(4):363-78.

9. Koch S, Rabinstein A, Falcone S, Forteza A. Diffusion-weighted imaging shows cytotoxic and vasogenic edema in eclampsia. Am $\mathbf{J}$ Neurorad. 2001;22:1068-70.

10. Kanki T, Tsukimori K, Mihara F, Nakano H. Diffusion-weighted images and vasogenic edema in eclampsia. Obstet Gynecol. 1999;93:821-3.

11. Fletcher JJ, Kramer AH, Bleck TP, Solenski NJ. Overlapping features of eclampsia and postpartum angiopathy. Neurocrit Care. 2009;11(2):199-209.

12. Shah AK, Rajamani K, Whitty JE. Eclampsia: a neurological perspective. J Neurol Sci. 2008;271:158-67.

13. Thomas SV. Neurological aspects of eclampsia. J Neurol Sci. 1998;155:37-43.

14. MacKay AP, Berg CJ, Atrash HK. Pregnancy-related mortality from preeclampsia and eclampsia. Obstet Gynecol. 2001;97(4):533-8.

15. Duley L. The global impact of preeclampsia and eclampsia. Semin Perinatol. 2009;33(3):130-7.

16. The Magpie Trial Collaborative Group. Do women with preeclampsia, and their babies, benefit from magnesium sulphate? The Magpie Trial: a randomized placebo-controlled trial. Lancet. 2002;359:1877-90.

17. Pritchard JA, Cunningham FG, Prichard SA. The Parklands memorial hospital protocol for treatment of eclampsia: evaluation of 245 cases. Am J obstet Gynecol. 1984:84:607-10.

18. Tong GM, Rude RK. Magnesium deficiency in critical illness. J Intensive Care Med. 2005;20:3-17.

19. Touyz RM. Role of magnesium in the pathogenesis of hypertension. Mol Aspects Med. 2003;24:107-36.
20. Idogun ES, Imarengiaye $\mathrm{CO}$, Momoh SM. Extracellular calcium and magnesium in preeclampsia and eclampsia. African J Reprod Health. 2007;11(2):89-94.

21. Meads CA, Cnossen JS, Meher S, Juarez-Garcia A, ter Riet G, Duley L, et al. Methods of prediction and prevention of preeclampsia: systematic reviews of accuracy and effectiveness literature with economic modeling. Health Technol Assess. 2008;12:3-4.

22. Sibai BM. Diagnosis, prevention, and management of eclampsia. Obstet Gynecol. 2005;105(2):402-10.

23. Douglas KA, Redman CWG. Eclampsia in the United Kingdom. BMJ. 1994;309:1395-400.

24. Katz VL, Farmer R, Kuller JA. Preeclampsia into eclampsia: toward a new paradigm. Am J Obstet Gynecol. 2000;182:1389-96.

25. Imaralu JO, Olaleye AO, Badejoko OO, Loto OM, Ogunniyi SO. The use of magnesium sulphate $\left(\mathrm{MgSO}_{4}\right)$ for seizure prophylaxis: clinical correlates in a Nigerian tertiary hospital. IJMBR. 2015;4:(2).

26. Preedatham K, Tansupswatdikul P. Serum magnesium level in severe preeclampsia and eclampsia patients, undergoing magnesium sulfate therapy at Chonburi hospital. Thai J Obstetr Gynaecol. 2009;17:190-5.

27. Phuapradit W, Saropala N, Haruvasin S, Thuvasethakul P. Serum level of magnesium attained in magnesium sulfate therapy for severe preeclampsia. Asia Oceania J Obstet Gynaecol. 1993;19(4):387-90.

28. Kirkwood BR, Sterne JAC. Essential Medical Statistics, $2^{\text {nd }}$ ed, Blackwell Science Ltd. Massachusetts; 2003:420.

29. Owolabi AT, Fatusi AO, Kuti O, Adeyemi AB, Faturoti SO, Obiajunwa PO. Maternal complications and outcomes in booked and unbooked Nigerian mothers. Singapore Med J. 2008;49(7):526-31.

30. Mattar F, Sibai BM. Eclampsia. VIII. Risk factors for maternal morbidity. Am J Obstet Gynecol. 2000;182(2):307-12.

31. Cooray SD, Edmonds SM, Tong S, Samarasekera SP, Whitehead CL. Characterization of symptoms immediately preceding eclampsia. Obstet Gynecol. 2011;118(5):995-9.

32. France J, Muganyizi P. Characteristics of symptoms of imminent eclampsia: a case referent study from a tertiary hospital in Tanzania. Open J Obstet Gynecol. 2012;2:311-7.

33. Knight M. Eclampsia in the United Kingdom 2005. BJOG. 2007;114:1072-8.

34. Hallak M, Berman RF, Irtenkauf SM, Janusz C, Cotton DB. Magnesium sulfate treatment decreases $\mathrm{N}$-methyl-D-aspartate receptor binding in the rat brain: an auto-radiographic study. J Soc Gynecol Invest. 1994;1:25-30.

35. Ekele BA, Badung SL. Is serum magnesium estimate necessary in patients with eclampsia on magnesium sulphate? Afr J Reprod Health. 2005;9:128-32.

36. Dayicioglu V, Sahinoglu Z, Kol E, Kucukbas M. The use of standard dose of magn esium sulphate in 
prophylaxis os eclamptic seizures; do BMI alterations have any effect on success? Hypetens Pregnancy. 2003:22(3):237-65.

37. Abbade JF, Costa RA, Martins AM, Borges VT, Ridge MV, Perocalli JC. Zuspans' scheme versus an alternative magnesium sulphate scheme; randomized clinical trial of magnesium serum concentrations. Hypertens Pregnancy. 2010;29(1):82-92.

Cite this article as: Imaralu JO, Badejoko OO, Loto OM, Ihongbe JC. Determinants of seizure occurrence in preeclampsia before commencing and during treatment with magnesium sulphate. Int J Reprod Contracept Obstet Gynecol 2016;5:3304-11. 